\title{
Comparison of Demographical Properties, Biochemical Parameters, Flow-mediated Dilatation Values and Carotis Intima Media Thickness of Patients with Coronary Artery Disease
}

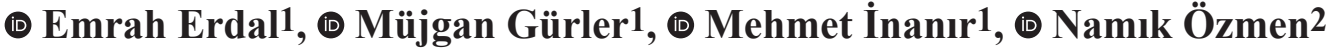

${ }^{1}$ Bolu Abant İzzet Baysal University Faculty of Medicine, Department of Cardiology, Bolu, Turkey

${ }^{2}$ Medical Park Hospital Bahçelievler, Clinic of Cardiology, İstanbul, Turkey

\begin{abstract}
Objectives: To compare demographic characteristics, biochemical parameters, flow-mediated dilatation (FMD) values and carotid intima-media thickness (CIMT) between older ( $>45$ years) and younger $(<45$ years) patients with coronary artery disease (CAD).
\end{abstract}

Materials and Methods: The present study comprised a total of 114 patients divided into four groups. For the study groups, group 1 had 30 patients with $\mathrm{CAD}<45$ years of age, and group 2 had 32 patients with $C A D>45$ years of age. Group 3 and group 4 were used as controls, comprising 28 ( $<45$ years) and 24 ( $>45$ years) healthy participants, respectively. Demographic characteristics, biochemical parameters, FMD values and CIMT were recorded and compared statistically among patients.

Results: The median age of patients was $47.81 \pm 14.50$ years. Hereditary risk factors and hyperlipidemia were statistically significant in group 1 than those in group 3 . Likewise, fasting blood glucose levels and CIMT values were statistically higher in group 1 than those in group 3 . Gender distribution and hyperlipidemia were statistically significant in group 2, in contrast to those in group 4 . The values of FMD was lower in group 2 than those in group 4 , which seemed to be statistically significant. The values of CIMT were higher whereas platelet counts were lower

Address for Correspondence: Emrah Erdal, Bolu Abant İzzet Baysal University Faculty of Medicine, Department of Cardiology, Bolu, Turkey e-mail: dr.emraherdal@gmail.com ORCID: orcid.org/0000-0002-3893-5376 Received: 08.02.2020 Accepted: 27.07.2020

Cite this article as: Erdal E, Gürler M, İnanır M, Özmen N. Comparison of Demographical Properties, Biochemical Parameters, Flow-mediated Dilatation Values and Carotis Intima Media Thickness of Patients with Coronary Artery Disease. EJCM 2020;8(3):131-137. DOI: 10.32596/ejcm.galenos.2020.01.03

Presented in: This study was published as oral presentation at the 14th International Update in Cardiology and Cardiovascular Surgery (UCCVS) Congress in Antalya, Turkey. 


\begin{abstract}
in group 2 than those in group 1, both findings of which were also statistically significant. The values of CIMT and Neutrophil/Lymphocyte (N/L) ratios increased whereas the values of FMD decreased significantly as the ages of participants increased.
\end{abstract}

Conclusion: The factors where $\mathrm{CAD}$ was more common in subjects were as follows: being over 45 years of age

\section{Introduction}

Cardiovascular disease is the most common cause of death worldwide and its prevalence is increasing in every last decade ${ }^{(1,2)}$. The incidence of coronary artery disease (CAD) is $1.2 \%$ under the age of 45 years and $7.1 \%$ over the age of 45 years and the incidence increases to $19 \%$ over the age of 65 years $^{(3)}$. Namely, the incidence of CAD increases as the age gets older.

In this study, demographic, biochemical and endothelial functions of patients older than 45 years and patients younger than 45 years were compared. We investigated the relationship between atherosclerosis and endothelial functions and carotid intima-media thickness (CIMT) with age.

We thought that it would be important to diagnose CAD early with a noninvasive test and to start treatment quickly. Especially, these noninvasive tests may be useful for selected patients who have CAD risk factors such as diabetes, genetic history, familial hypercholesterolemia, etc.

\section{Materials and Methods}

The present study comprised a total of 114 patients divided into four groups. For the study groups, group 1 had 30 patients with CAD $<45$ years of age, and group 2 had 32 patients with CAD $>45$ years of age. Group 3 and group 4 were used as controls, comprising 28 ( $<45$ years) and 24 ( $>45$ years) healthy participants, respectively. Ethics committee approval for the study was obtained
(2.36 times), the presence of hyperlipidemia (3.58 times), increased $\mathrm{N} / \mathrm{L}$ ratios (1.6 times), a combination of increased CIMT values and age (12 times), and decreased FMD values (2 times).

Keywords: Carotid intima-media thickness, coronary artery disease, endothelial dysfunction, flow-mediated dilatation values

from Zeynep Kamil Hospital, with June 2015 protocol number 78, İstanbul, Turkey. Informed consent for the study and the investigation was received from each patient in accordance with the principles outlined in the Declaration of Helsinki.

Demographic characteristics, biochemical parameters, FMD values and CIMT were recorded and compared statistically among patients.

The patients who had their coronary artery stenosis at least $30 \%$ after performing coronary angiography were included in the study. Participants with normal coronary angiography were also included in the control group. The FMD test was performed after 8-12 hours of fasting for all participants. Alcohol, caffeine and vasodilator medication were not provided 12 hours before the FMD test. Brachial artery (BA) was found in antecubital fossa with Philips IE33 $X$ MATRIX echo device and L11-3 probe at room temperature $\left(21-25^{\circ} \mathrm{C}\right)$. The anterior-posterior wall and lumen of the BA were imaged. Three different measurements were made in the diastole according to electrocardiography (ECG) for BA diameter (intima to intima). Averages of these three measurements were taken for basal BA diameter. The blood pressure device was inflated over $50 \mathrm{mmHg}$ of systolic blood pressure and waited for 5 minutes so the flow was cut off and the ischemia occurred. Then, the blood pressure device was deflated. One minute later, three different measurements were made in the diastole according to ECG for ischemic 
BA diameter. FMD was calculated using this formula; FMD: Ischemic BA diameter - basal BA diameter/ basal BA diameter $\times 100^{(4,5)}$. Then, the right common carotid artery was visualized. Intima-media thickness measurement was performed from the posterior wall. Three measurements were made and averaged ${ }^{(6,7)}$. In healthy population, normal CIMT was accepted as 0.25 $1.0 \mathrm{~mm}$. CIMT increased by 0.01-0.02 $\mathrm{mm}$ per year associated with age.

\section{Exclusion Criteria}

1. Individuals under the age of 18 years

2. Carotid revascularization that was previously performed

3. Those with a history of previous cerebrovascular events (CVO)

4. Those with collagen tissue disease

5. Patients whose carotid or brachial arteries were not well visualized

\section{Statistical Analysis}

Statistical analyses were performed using the IBMSPSS Statistics version 20 software (SPSS Inc., Chicago, Illinois). In the comparison of quantitative data, the MannWhitney $U$ test was used to determine the difference between the two groups. For the comparison of categorical variables, the chi-square test was used. Pearson correlation coefficient was employed to determine relationships. $P$ values less than 0.05 were accepted to be statistically significant.

\section{Results}

The median age of patients was $47.81 \pm 14.50$ years. Hereditary risk factors and hyperlipidemia were statistically significant in group 1 than those in group 3 (Table 1). Likewise, fasting blood glucose levels and CIMT values were statistically higher in group 1 than those in group 3. But, FMD values were not statistically significant between group 1 and group 3 (Table 2). Gender distribution and hyperlipidemia were statistically significant in group 2 , in contrast to those in group 4 (Table 3 ). The values of FMD were lower in group 2 than those in group 4, which seemed to be statistically significant (Table 4 ). The values of CIMT were higher whereas platelet counts were lower in group 2 than those in group 1, both findings of which were also statistically significant (Table 5). N/L ratio and CIMT values were higher in group 4, compared to group 3 (Table 6). The values of CIMT and neutrophil/ lymphocyte (N/L) ratios increased whereas the values of FMD decreased significantly as the ages of participants increased (Table 7).

\section{Discussion}

In patients under 45 years of age, when compared to the control group under the age of 45 years, the value of CIMT was found to be statistically significantly higher. Similar to our findings, Limbu et al. ${ }^{(8)}$ found that ultrasonographic measurement of CIMT was valuable in young individuals with CAD risk factors. On the other hand, CIMT values were similar between patients older than 45 years and its control group. These results suggest that CIMT measurements may be more useful in predicting CAD especially in young patients with risk

Table 1. Controllable risk factors in individuals younger than 45 years

\begin{tabular}{|c|c|c|c|c|}
\hline & & $\begin{array}{l}\text { Patients, under } \\
45 \text { years } \\
\text { of age } \\
\text { group } 1\end{array}$ & $\begin{array}{l}\text { Control group, } \\
\text { under } 45 \text { years } \\
\text { of age } \\
\text { group } 3\end{array}$ & $p$ \\
\hline \multirow{2}{*}{ Sex } & Male & $21(91.3 \%)$ & $23(82.14 \%)$ & \multirow{2}{*}{0.44} \\
\hline & Female & $2(8.7 \%)$ & $5(17.86 \%)$ & \\
\hline \multirow{2}{*}{ Smoking } & No & $14(60.87 \%)$ & $19(67.86 \%)$ & \multirow{2}{*}{0.6} \\
\hline & Yes & $9(39.13 \%)$ & $9(32.14 \%)$ & \\
\hline \multirow{2}{*}{ HT } & No & 17 (73.91\%) & $25(89.29 \%)$ & \multirow{2}{*}{0.27} \\
\hline & Yes & $6(26.09 \%)$ & $3(10.71 \%)$ & \\
\hline \multirow{2}{*}{ HL } & No & $11(47.83 \%)$ & $26(92.86 \%)$ & \multirow{2}{*}{$0.0001^{*}$} \\
\hline & Yes & $12(52.17 \%)$ & $2(7.14 \%)$ & \\
\hline \multirow{2}{*}{ DM } & No & $19(82.61 \%)$ & $26(92.86 \%)$ & \multirow{2}{*}{0.39} \\
\hline & Yes & $4(17.39 \%)$ & $2(7.14 \%)$ & \\
\hline \multirow{2}{*}{ Heredity } & No & $6(26.09 \%)$ & $15(53.57 \%)$ & \multirow{2}{*}{$0.047^{*}$} \\
\hline & Yes & $17(73.91 \%)$ & $13(46.43 \%)$ & \\
\hline
\end{tabular}


Table 2. Comparison of FMD, CIMT and biochemical parameters between group 1 and group 3

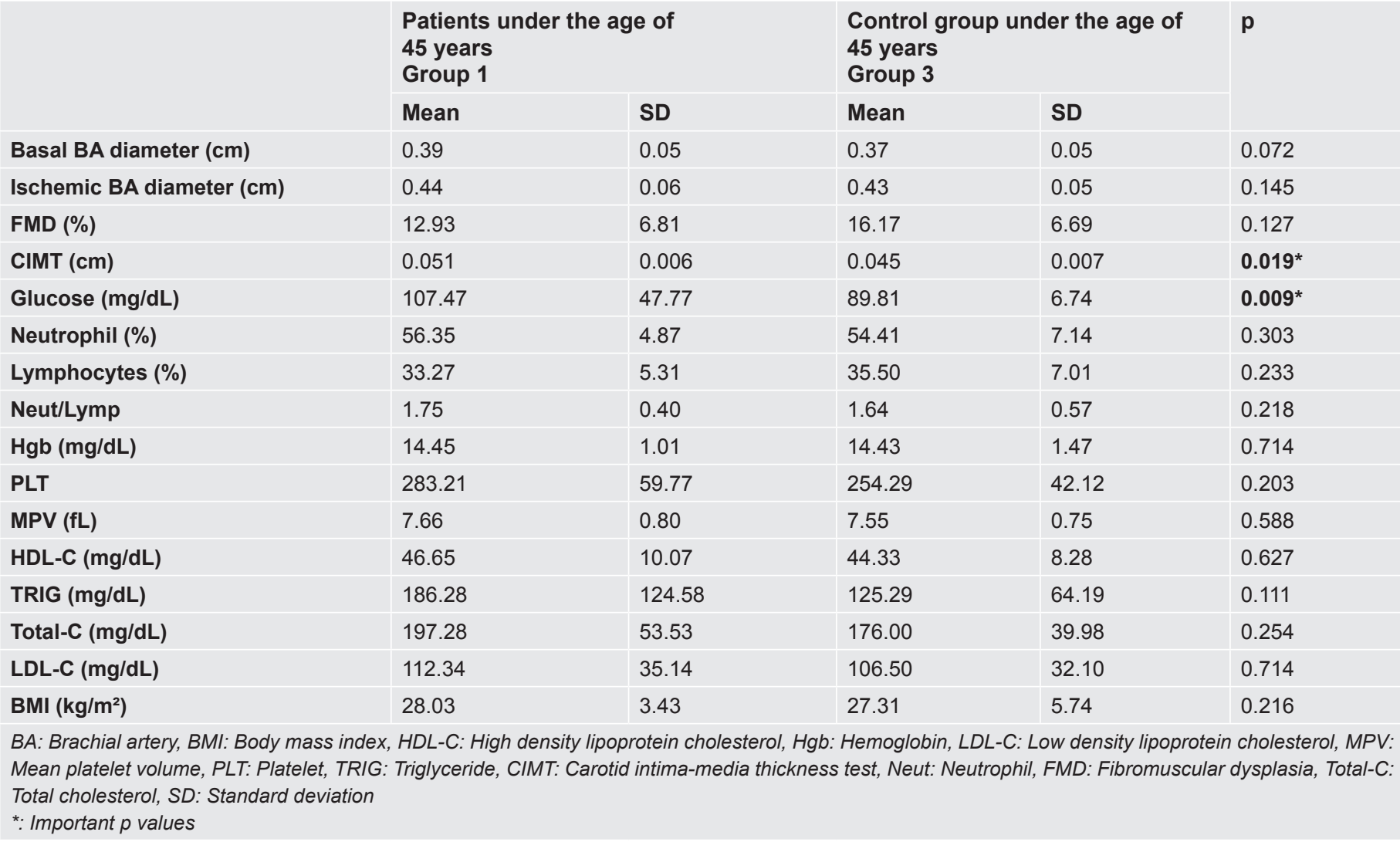

Table 3. Controllable risk factors in individuals older than 45 years

\begin{tabular}{|c|c|c|c|c|}
\hline & & $\begin{array}{l}\text { Patients over the age of } 45 \\
\text { years } \\
\text { Group } 2\end{array}$ & $\begin{array}{l}\text { Control group over the age of } \\
45 \text { years } \\
\text { Group } 4\end{array}$ & $\mathbf{p}$ \\
\hline Sex & Male & $22(88 \%)$ & $9(37.5 \%)$ & $0.0001^{*}$ \\
\hline \multirow{2}{*}{ Smoking } & No & $15(60 \%)$ & $18(75 \%)$ & \multirow{2}{*}{0.26} \\
\hline & Yes & $10(40 \%)$ & $6(25 \%)$ & \\
\hline HT & Yes & $19(76 \%)$ & $12(50 \%)$ & 0.059 \\
\hline \multirow{2}{*}{ HL } & No & $2(8 \%)$ & $17(70.83 \%)$ & \multirow{2}{*}{$0.0001^{*}$} \\
\hline & Yes & $23(92 \%)$ & $7(29.17 \%)$ & \\
\hline \multirow{2}{*}{ DM } & No & $17(68 \%)$ & $21(87.5 \%)$ & \multirow{2}{*}{0.102} \\
\hline & Yes & $8(32 \%)$ & $3(12.5 \%)$ & \\
\hline
\end{tabular}


factors such as hyperlipidemia, diabetes and heredity. Thus, these patients may be treated more aggressively in advance. On the other hand, the value of FMD was found to be higher in patients older than 45 years than its control group. Similarly, in the study of Ono et al. ${ }^{(9)}$, there were 292 patients with diabetes (mean age, $65 \pm 12$ years; $59 \%$ men) and statistically significant correlation was found between coronary artery calcification and FMD values. In addition, ultrasonographic measurement of CIMT and FMD is an easy and inexpensive method. Our study showed that the measurement of FMD could also provide more valuable information in patients over 45 years of age.

Table 4. Comparison of FMD, CIMT and biochemical parameters between group 2 and group 4

\begin{tabular}{|c|c|c|c|c|c|}
\hline & \multicolumn{2}{|c|}{$\begin{array}{l}\text { Patients over } \\
\text { the age of } 45 \\
\text { years } \\
\text { Group } 2\end{array}$} & \multicolumn{2}{|c|}{$\begin{array}{l}\text { Control group } \\
\text { over the age } \\
\text { of } 45 \text { years } \\
\text { Group } 4\end{array}$} & \multirow[t]{2}{*}{$\mathbf{p}$} \\
\hline & Mean & SD & Mean & SD & \\
\hline $\begin{array}{l}\text { Basal BA diameter } \\
(\mathrm{cm})\end{array}$ & 0.42 & 0.06 & 0.37 & 0.05 & $0.006^{*}$ \\
\hline $\begin{array}{l}\text { Ischemic BA diameter } \\
(\mathrm{cm})\end{array}$ & 0.47 & 0.05 & 0.43 & 0.06 & $0.010^{*}$ \\
\hline FMD (\%) & 11.67 & 8.06 & 14.70 & 6.25 & 0.075 \\
\hline CIMT (cm) & 0.065 & 0.01 & 0.062 & 0.01 & 0.357 \\
\hline Glucose (mg/dL) & 115.16 & 48.90 & 100.96 & 41.45 & 0.269 \\
\hline Neut (\%) & 59.34 & 8.02 & 57.66 & 6.56 & 0.457 \\
\hline Lym (\%) & 29.89 & 7.24 & 31.57 & 6.08 & 0.436 \\
\hline Neut/Lym & 2.17 & 0.85 & 1.94 & 0.59 & 0.624 \\
\hline $\mathrm{Hgb}(\mathrm{mg} / \mathrm{dL})$ & 14.39 & 1.57 & 13.74 & 1.44 & 0.092 \\
\hline PLT & 213.31 & 69.33 & 241.39 & 64.75 & 0.154 \\
\hline MPV (fL) & 8.26 & 1.35 & 7.85 & 0.91 & 0.483 \\
\hline HDL-C (mg/dL) & 45.80 & 9.84 & 58.52 & 19.83 & $0.035^{*}$ \\
\hline TRIG (mg/dL) & 152.08 & 82.58 & 144.57 & 111.13 & 0.434 \\
\hline Total-C (mg/dL) & 187.44 & 29.30 & 222.57 & 59.43 & $0.037^{*}$ \\
\hline LDL-C (mg/dL) & 111.92 & 28.72 & 138.02 & 45.02 & $0.028^{*}$ \\
\hline BMI & 27.12 & 4.73 & 27.69 & 4.49 & 0.764 \\
\hline \multicolumn{6}{|c|}{$\begin{array}{l}\text { BA: Brachial artery, BMI: Body mass index, HDL-C: High density lipoprotein } \\
\text { cholesterol, Hgb: Hemoglobin, LDL-C: Low density lipoprotein cholesterol, } \\
\text { MPV: Mean platelet volume, PLT: Platelet, TRIG: Triglyceride, CIMT: } \\
\text { Carotid intima-media thickness test, Neut: Neutrophil, Lym: Lymphocyte, } \\
\text { FMD: Fibromuscular dysplasia, Total-C: Total cholesterol, SD: Standard } \\
\text { deviation } \\
* \text { *: Important p values }\end{array}$} \\
\hline
\end{tabular}

In our study, FMD values were not statistically significant between group 1 and group 3. Unlike, in the study of Kaźmierski et al. ${ }^{(10)}$, FMD values were found to be significantly lower in patients younger than 45 years compared to the control group.

A significant positive correlation was found between CIMT value and N/L ratio in our study. Similar to our findings, Demirkol et al. ${ }^{(11)}$ found a significant positive correlation between the CIMT value and the plasma $\mathrm{N} / \mathrm{L}$ ratio. We found a negative correlation between FMD and CIMT. Likewise, Chequer et al. ${ }^{(12)}$ showed a statistically significant relationship between CIMT and FMD in their study. We found that the FMD value decreased significantly with age. Similarly, in a study on 2,511 Chinese adults, there was a negative correlation between age and $\mathrm{FMD}^{(13)}$. Again, there was also an inverse relationship between age and FMD in the study of Kirma et al. ${ }^{(14)}$ In this study, carotid plaques were not evaluated, only CIMT measurements were performed. However, in previous studies, carotid plaques were more important than CIMT for prognosis especially in cardiac events. Yuk et al. ${ }^{(15)}$ showed that carotid plaques were more important than CIMT in determining the prognosis of cardiac events in patients with CAD.

Table 5. Comparison of FMD, CIMT and biochemical parameters between group 1 and group 2

\begin{tabular}{|c|c|c|c|}
\hline & $\begin{array}{l}\text { Patients under } \\
\text { the age of } 45 \\
\text { years }\end{array}$ & $\begin{array}{l}\text { Patients over } \\
\text { the age of } 45 \\
\text { years }\end{array}$ & $p$ \\
\hline & Group 1 & Group 2 & \\
\hline FMD (\%) & $12.93 \pm 6.81$ & $11.67 \pm 8.06$ & 0.42 \\
\hline CIMT (cm) & $0.051 \pm 0.006$ & $0.065 \pm 0.01$ & $0.001^{*}$ \\
\hline Glu (mg/dL) & $107.47 \pm 47.77$ & $115.16 \pm 48.9$ & 0.80 \\
\hline Neut/Lym ratio & $1.75 \pm 0.4$ & $2.17 \pm 0.85$ & 0.17 \\
\hline $\mathrm{Hgb}(\mathrm{mg} / \mathrm{dL})$ & $14.45 \pm 1.01$ & $14.39 \pm 1.57$ & 0.81 \\
\hline Platelet & $283.21 \pm 59.77$ & $213.31 \pm 69.33$ & $0.001^{*}$ \\
\hline MPV (fL) & $7.66 \pm 0.8$ & $8.26 \pm 1.35$ & 0.21 \\
\hline HDL-C (mg/dL) & $46.65 \pm 10.07$ & $45.8 \pm 9.84$ & 0.93 \\
\hline TG (mg/dL) & $186.28 \pm 124.58$ & $152.08 \pm 82.58$ & 0.48 \\
\hline \multicolumn{4}{|c|}{$\begin{array}{l}\text { CIMT: Carotid intima media thickness, FMD: Flow mediated dilatation, Glu. } \\
\text { Glucose, HDL-C: High density lipoprotein cholesterol, Hgb: Hemoglobin, } \\
\text { Lym: Lymphocyte, MPV: Mean platelet volume, Neut: Neutrophil, TG. } \\
\text { Triglyceride } \\
\text { *: Important } p \text { values }\end{array}$} \\
\hline
\end{tabular}


According to our results, the factors where CAD was more common in subjects were as follows: being over 45 years of age (2.36 times), the presence of hyperlipidemia (3.58 times), increased N/L ratios (1.6 times), a combination of increased CIMT values and age (12 times), and decreased FMD values (2 times).

\section{Study Limitations}

The present study has a small population size. One of the limitations of our study was that the relationship between FMD and CIMT values and future coronary events was not evaluated. The other limitation is that we did not evaluate the carotid plaques, we only measured the CIMT. So, it would be more useful for researchers to evaluate both in their studies. Future studies are needed to confirm our finding and evaluate the usefulness of CIMT and FMD as a surrogate marker of $\mathrm{CAD}$ and future cardiovascular

Table 6. Comparison of FMD, CIMT and biochemical parameters between group 3 and group 4

\begin{tabular}{|l|l|l|l|}
\hline & Group 3 & Group 4 & $\mathbf{p}$ \\
\hline FMD (\%) & $16.17 \pm 6.69$ & $14.7 \pm 6.25$ & 0.53 \\
\hline CIMT (cm) & $0.045 \pm 0.007$ & $0.062 \pm 0.01$ & $0.001^{*}$ \\
\hline Glu (mg/dL) & $89.81 \pm 6.74$ & $100.96 \pm 41.45$ & 0.64 \\
\hline Neu/Lym ratio & $1.64 \pm 0.57$ & $1.94 \pm 0.59$ & 0.05 \\
\hline Hgb (mg/dL) & $14.43 \pm 1.47$ & $13.74 \pm 1.44$ & 0.13 \\
\hline Platelet count & $254.29 \pm 42.12$ & $241.39 \pm 64.75$ & 0.42 \\
\hline MPV (fL) & $7.55 \pm 0.75$ & $7.85 \pm 0.91$ & 0.24 \\
\hline HDL (mg/dL) & $44.33 \pm 8.28$ & $58.52 \pm 19.83$ & $0.02^{*}$ \\
\hline TG (mg/dL) & $125.29 \pm 64.19$ & $144.57 \pm 111.13$ & 0.89 \\
\hline $\begin{array}{l}\text { CIMT: Carotid intima } \text { media thickness, FMD: Flow mediated dilatation, } \\
\text { Glu: Glucose, HDL: High density lipoprotein, Hgb: Hemoglobin, Lym: } \\
\text { Lymphocyte, MPV: Mean platelet volume, Neu: Neutrophil, TG: Triglyceride }\end{array}$ \\
*: Important p values & &
\end{tabular}

Table 7. Relationship between age and other variables: As age increases, FMD values and PLT counts decrease. CIMT and MPV values increase. These are all statistically significant

\begin{tabular}{|l|l|l|}
\hline Age & $\mathbf{r}$ & $\mathbf{p}$ \\
\hline FMD & -0.230 & 0.022 \\
\hline CIMT & 0.707 & 0.0001 \\
\hline PLT & -0.292 & 0.006 \\
\hline MPV & 0.212 & 0.048 \\
\hline CIMT: Carotid intima media thickness, FMD: Flow mediated dilatation, \\
\hline MPV: Mean platelet volume, PLT: Platelet
\end{tabular}

events.

\section{Conclusion}

In conclusion, it may be meaningful to evaluate the CIMT value for primer protection in younger individuals, especially those with risk factors, and these patients may be treated more aggressively.

\section{Ethics}

Ethics Committee Approval: There is ethics committee approval from Zeynep Kamil Hospital, June 2015 protocol number 78, İstanbul, Turkey for the study.

Informed Consent: Informed consent for the study and the investigation was received from each patient in accordance with the principles outlined in the Declaration of Helsinki.

Peer-review: Internally and externally peer-reviewed.

\section{Authorship Contributions}

Surgical and Medical Practices: E.E., M.G., M.İ., N.Ö., Concept: E.E., M.G., M.İ., N.Ö., Design: E.E., M.G., M.İ., N.Ö., Data Collection or Processing: E.E., Analysis or Interpretation: E.E., M.İ., Literature Search: E.E., Writing: E.E.

Conflict of Interest: Authors have declared that no competing and conflict of interest exist.

Financial Disclosure: This study was not supported by any institution or organization.

\section{References}

1. Tokgözoğlu L. Atherosclerosis and the role of inflammation. Turk Kardiyol Dern Ars 2009;37(Suppl 4):1-6.

2. Braunwald, Zipes, Libby-Bonow. A Textbook of Cardiovascular Medicine. ed 8, p 1103-27.

3. Hu FB, Stampfer MJ, Manson JE, et al. Trends in the incidence of coronary heart disease and changes in diet an lifestyle in women. $\mathrm{N}$ Engl $\mathrm{J}$ Med 2000;343:530-7.

4. Corretti MC, Anderson TJ, Benjamin EJ, et al. Guidelines for the ultrasound assessment of endothelial-dependent flow-mediated vasodilation of the brachial artery: a report of the International Brachial Artery Reactivity Task Force. J Am Coll Cardiol 2002;39:257-65.

5. Deanfield J, Donald A, Ferri C, et al. Endothelial function and dysfunction. Part I: Methodological issues for assessment in the different vascular beds: 
a statement by the Working Group on Endothelin and Endothelial Factors of the European Society of Hypertension. J Hypertens 2005;23:7-17.

6. Wong M, Edelstein J, Wollman J, Bond MG. Ultrasonic-pathological comparison of the human arterial wall: verification of intima-media thickness. ArterioscleThromb 1993;13:482-6.

7. Ebrahim S, Papacosta O, Whincup P, et al. Carotid plaque, intima media thickness, cardiovascular risk factors, and prevalent cardiovascular disease in men and women: the British Regional Heart Study. Stroke 1999;30:84150 .

8. Limbu YR, Rajbhandari R, Sharma $\mathrm{R}$, et al. Carotid intima-media thickness (CIMT) and carotid plaques in young Nepalese patients with angiographically documented coronary artery disease. Cardiovasc Diagn Ther 2015;5:1-7.

9. Ono T, Miyoshi T, Ohno Y, et al. Brachial intima-media thickness is associated with coronary arteryatherosclerosis in patients with diabetes mellitus. Heart Vessels 2019;34:1405-11.

10. Kaźmierski M, Michalewska-Włudarczyk A, Krzych LJ, Tendera M. Diagnostic value of flow mediated dilatation measurement forcoronary artery lesions in men under 45 years of age. Cardiol J 2010;17:288-92.
11. Demirkol S, Balta S, Unlu M, et al. Neutrophils/lymphocytes ratio in patients with cardiac syndrome $\mathrm{X}$ and its association with carotid intimamedia thickness. Clin Appl Thromb Hemost 2014;20:250-5.

12. Chequer G, Nascimento BR, Navarro TP, et al. Carotid intimal-medial thickening and endothelial function incoronary artery disease. Arq Bras Cardiol 2006;87:84-90.

13. Yang PT, Yuan H, Wang YQ, Cao X, Wu LX, Chen ZH. Correlations between brachial endothelial function and cardiovascular risk factors: a survey of 2,511 Chinese subjects. J Thorac Dis 2014;6:1441-51.

14. Kirma C, Akcakoyun M, Esen AM, et al. Relationship between endothelial function andcoronary risk factors in patients with stablecoronary artery disease. Circ J 2007;71:698-702.

15. Yuk HB, Park HW, Jung IJ, et al. Analysis of Carotid Ultrasound Findings on Cardiovascular Events in Patients with Coronary ArteryDiseaseduring Seven-Year Follow-Up. Korean Circ J 2015;45:28-37. 